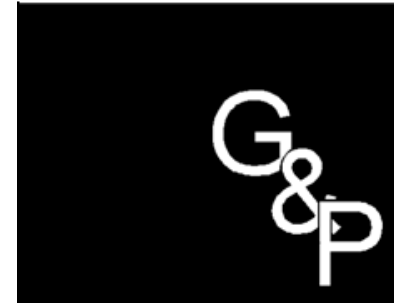

GESTÃO

$\&$

PRODUÇÃO

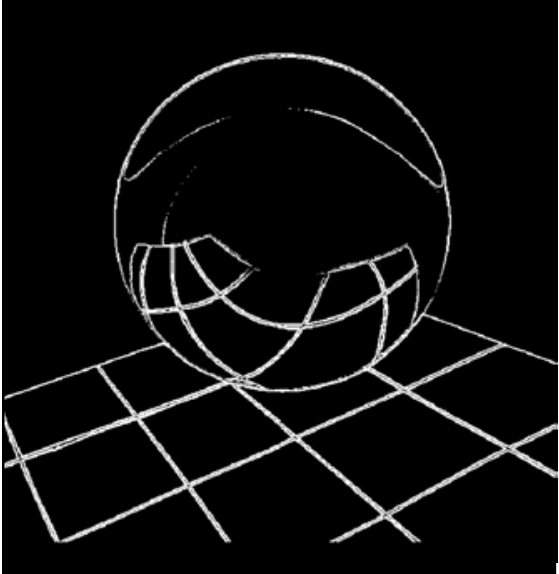

v.7, n.1, p. 56-72, abr. 2000

\section{COLABORAÇÃO CLIENTE- FORNECEDOR NO PROCESSO DE DESENVOLVIMENTO DE PRODUTO: ESTUDO DE CASOS NA INDÚSTRIA DE AUTOPEÇAS}

\author{
Daniel Capaldo Amaral \\ Programa de Engenharia Mecânica \\ Escola de Engenharia de São Carlos-USP \\ E-mail: amaral@sc.usp.br \\ José Carlos de Toledo \\ Departamento de Engenharia de Produção \\ Universidade Federal de São Carlos \\ E-mail: toledo@power.ufscar.br
}

\title{
Resumo
}

Uma das práticas utilizadas pelas empresas, visando o aumento da produtividade, qualidade e diminuição do lead time do desenvolvimento de produto, é a inclusão dos fornecedores neste processo. Apesar de já demonstrado que esta participação tem impactos importantes no processo de desenvolvimento, ainda existe pouca compreensão sobre seus reais efeitos no desempenho deste processo, principalmente quanto aos efeitos na qualidade do projeto do produto. Analisa-se, sob a ótica do fornecedor, as variáveis escopo e integração, em dois casos especificos deste tipo de colaboração na indústria automobilística brasileira. Para cada caso, analisa-se essas variáveis em projetos de desenvolvimento conjunto entre a empresa de autopeça e seus clientesmontadoras e discute-se a relação destas variáveis com a qualidade do projeto do produto. Como resultados principais, válidos para os casos analisados, tem-se que: os mecanismos formais da colaboração cliente-fornecedor no desenvolvimento de produto foram homogêneos, entre cada autopeça e seus clientes-montadoras; e o aumento do escopo afetou positivamente a qualidade do projeto do produto.

Palavras-chave: desenvolvimento de produto, colaboração cliente-fornecedor, qualidade do projeto do produto, indústria de autopeças. 


\section{Introdução}

A participação dos fornecedores de forma sistemática no processo de desenvolvimento de produto é uma prática que tem disseminado-se por diversas indústrias e países na década de noventa. Segundo NISHIGUSHI (1993), ela se originou nas indústrias automobilística e eletrônica japonesas, principalmente após 1950, como reflexo de uma situação socioeconômica (a guerra da Coréia, o plano Dodge, o ressurgimento do sindicalismo, entre outros acontecimentos anteriores) que estruturou um sistema de subcontratação caracterizado pela hierarquização e forte relacionamento entre as empresas fornecedoras e clientes, incluindo neste relacionamento o envolvimento dos fornecedores no processo de desenvolvimento de produto. Este sistema ficou bastante conhecido na década de noventa como sendo um dos aspectos fundamentais do novo paradigma de produção japonês, e se disseminou para as demais indústrias e países. Dentro deste contexto, surgiu a tendência, que se intensifica, de participação dos fornecedores no processo de desenvolvimento de produto, principalmente na indústria automobilística mundial.

Apesar de sua rápida evolução, os reais efeitos da participação de fornecedores no processo de desenvolvimento de produto ainda não são bem compreendidos. Há fortes evidências de que este tipo de colaboração aumenta a produtividade e diminui o lead time de desenvolvimento (CLARK, 1989; CLARK \& FUJIMOTO, 1991; e BROWN \& EISENHARDT, 1995), diminui a chance de atrasos no projeto (HARTLEY, ZIRGER \& KAMATH, 1996) e facilita a incorporação de novas tecnologias (IMAI, NONAKA \& TAKEUSHI, 1985; LITTLER et al. (1996); RAGATZ, HANDFIELD \& SCANNEL, 1997). Outra evidência identificada é que a capacidade técnica gerada no fornecedor, a partir deste tipo de relacionamento, transforma-o numa fonte hábil e flexível para a resolução dos problemas dos clientes, além de uma fonte potencial para inovação tecnológica de seus produtos (IMAI, NONAKA \&
TAKEUSHI, 1985; e NISHIGUCHI, 1993).

No entanto, há trabalhos que apontam efeitos negativos (por exemplo, LITTLER et al., 1995) e outros que apresentam diversas barreiras para sua aplicação (RAGATZ, HANDFIELD \& SCANNEL, 1997; LARSON \& DREXLER, 1997). Um dos pontos mais críticos é o efeito, dessa participação, na qualidade do projeto do produto final. Nas medições de CLARK \& FUJIMOTO (1991) e CLARK (1989), o envolvimento dos fornecedores no processo de desenvolvimento teve uma influência negativa na qualidade do produto. Da mesma forma, BIDAULT, DESPRESS \& BUTLER (1998) encontraram, num survey sobre esse tema, que esta prática diminui a integridade do produto e HARTLEY et al. (1997) mostram que o envolvimento dos fornecedores, no desenvolvimento de produto, não necessariamente leva a uma melhor solução técnica.

A dificuldade de responder a esta questão dos efeitos está na própria ausência de compreensão sobre os mecanismos organizacionais que suportam este trabalho conjunto e a influência do tipo de contribuição prestada pelo fornecedor, ou seja, do tipo de atividade de desenvolvimento por ele realizada. E este é um ponto central na questão da participação dos fornecedores no processo de desenvolvimento de produto. Isto fica nítido no trabalho de LIKER et al. (1996) no qual se demonstra, num levantamento extenso de dados, que não há grandes diferenças estruturais nas cadeias de fornecimento da indústria americana e japonesa, sendo as diferenças em desempenho devida às peculiaridades dos mecanismos organizacionais e técnicos que suportam a relação.

Isto é, ao delegar parte do processo de desenvolvimento para o fornecedor surge um novo desafio que é o de gerenciar e coordenar o desenvolvimento conjunto entre as duas equipes, de forma a manter a integridade do produto final. Assume-se Integridade no sentido proposto por CLARK \& FUJIMOTO (1991), que é de um efetivo balanceamento entre as características de qualidade do produto. 
$\mathrm{Na}$ realidade, desde os primeiros projetos de automóveis e produtos mais complexos já existia uma intensa participação dos fornecedores no processo de desenvolvimento de produto das empresas-clientes (NISHIGUCHI, 1994). Com o tempo, a intensificação da produção em massa e a integração vertical que acompanhava este modelo, esta prática tornou-se rara. As empresas-clientes, grandes complexos fabris integrados, passaram a projetar totalmente o produto incluindo as peças que não seriam produzidas por elas mesmas. Isto não significa que a participação de fornecedores deixou de existir, mas tornou-se inexpressiva e pouco significativa, relegada a casos isolados. O que há de novidade na intensificação desta prática iniciada no Japão na década de 50 , e que se disseminou no ocidente a partir dos anos 90, é a busca sistemática da inclusão dos fornecedores no processo de desenvolvimento com o intuito de obter melhorias e vantagens econômicas, ou seja, com objetivos estratégicos.

Desde então muitos nomes têm sido empregados para designar este movimento. Desde o mais simples como participação dos fornecedores no processo de desenvolvimento de produto como também codesign, cooperação, colaboração, outsourcing de projetos, design chain, entre outros. Adota-se, neste trabalho, o termo Colaboração pois é o que, no idioma português, expressa o fenômeno com maior neutralidade, sem juízos de valor de caráter positivo. Segundo Aurélio (1988), um dos significados de colaboração, aqui adotado, é o de trabalho conjunto entre pessoas, neste caso empresas. Assim, durante este trabalho esta prática será referida como Colaboração entre clientes e fornecedores no processo de desenvolvimento de produto.

$\mathrm{O}$ artigo contribui para a compreensão da influência na qualidade do produto devida à colaboração cliente-fornecedor no processo de desenvolvimento de produto. Isto é importante por ser este tipo de colaboração uma tendência crescente no meio industrial, fazendo com que o aumento de sua compreensão possa gerar informações úteis tanto para empresas clientes, sobre como gerenciar o processo de desenvolvimento de seus produtos de forma a incorporar o apoio dos fornecedores com uma interferência positiva na qualidade final do produto, como para os fornecedores, tal que moldem suas ações de forma a proporcionar uma efetiva contribuição no processo de desenvolvimento de seus clientes.

Durante a análise inicial deste problema duas variáveis pareceram potencialmente mais importantes para o entendimento deste relacionamento, que são o escopo do projeto do fornecedor e a integração inter-organizacional. A primeira diz respeito à quantidade e aos tipos de atividade de desenvolvimento realizada pelo fornecedor. Já a integração refere-se aos mecanismos e intensidade da troca de informação entre as equipes de desenvolvimento, do cliente e do fornecedor. Utilizando estas variáveis foram realizados estudos de caso em duas empresas de autopeça, analisando as colaborações entre estas empresas e seus clientes.

O objetivo do trabalho é caracterizar, em duas empresas brasileiras de autopeças, as variáveis "integração" e "escopo do projeto" nas colaborações cliente-fornecedor no desenvolvimento de produto, entre a autopeça e cada um de seus clientes (montadoras), e discutir a interelação destas variáveis com a "qualidade do projeto do produto".

\section{A Colaboração Cliente-fornecedor no Processo de Desenvolvimento de Produto}

colaboração cliente-fornecedor no desen$\mathbf{A}_{\text {volvimento de produto é aqui definida }}$ como a entidade organizacional formada pela união de todas as pessoas, recursos e mecanismos de interação das estruturas organizacionais de desenvolvimento de uma empresa cliente e uma fornecedora engajadas num mesmo processo de desenvolvimento (este conceito foi desenvolvido com base em ACHROL et al., 1990 e LAMMING, 1993).

A seguir são apresentadas as definições das variáveis utilizadas na pesquisa: 
Escopo do Fornecedor: quantidade de cada fase do processo de desenvolvimento realizada pelo fornecedor. Para a análise do escopo utilizou-se como critério a tipologia de peças desenvolvida por CLARK \& FUJIMOTO (1991). Esse modelo estabelece os tipos de peças desenvolvidas como Peças de Controle Detalhado do Fornecedor, Black Box e Peças de Controle Detalhado do Cliente (classificadas em: Peças de Carroceria e Peças Funcionais). Desta forma, determinando-se, para cada cliente, quais os tipos de projetos de desenvolvimento mais freqüentes, é possível caracterizar, de uma forma geral, o grau de participação do fornecedor nos projetos para esse cliente. Durante as entrevistas preparatórias para esta pesquisa esta tipologia foi adaptada para o caso brasileiro, onde não existe claramente a distinção entre dois tipos de Peças de Controle Detalhado do Cliente descritos por esses autores (Peças de Carroceria e Peças Funcionais). Havia sim uma clara distinção entre projetos desenvolvidos pela filial da montadora no Brasil e projetos transplantados, nos quais o cliente entrega o projeto para o fornecedor, desenvolvido na matriz dessa montadora, dando liberdade para alterações conforme as necessidades do seu processo produtivo. Portanto, foi criado o tipo Adaptação de Peças de Controle Detalhado do Cliente. A tipologia adotada é apresentada na Tabela 1.

Integração: quantidade e tipo de Comunicação, Compatibilidade e Cooperação entre as estruturas organizacionais de desenvolvimento do cliente e do fornecedor, estratificadas por níveis: estratégico, tático, operacional e pessoal. Combinando os três tipos de integração com estes níveis tem-se 9 dimensões da variável integração, que foi reduzida para 8 na medida que uma delas não faz sentido. Essas dimensões foram desenvolvidas a partir de uma ampla revisão bibliográfica sobre integração e são apresentadas detalhadamente em AMARAL (1997) e AMARAL, TOLEDO \& TAHARA (1998). As definições das dimensões são apresentadas na Tabela 2 .
Qualidade do Projeto do Produto: características de qualidade do subsistema (produto a ser suprido pelo fornecedor para o cliente) consolidadas nas fases de projeto do produto e do processo, até a produção piloto. Essas características são apresentadas em TOLEDO (1994). Elas serviram de base para a análise da inter-relação das variáveis escopo e integração com a qualidade do projeto do produto (subsistema).

\section{Método}

$\mathrm{P}$ ara caracterizar a integração e o escopo do projeto na colaboração cliente-fornecedor no desenvolvimento de produto das empresas pesquisadas delimitou-se a unidade de análise como sendo a colaboração entre o fornecedor e cada um de seus clientes específicos. Dessa forma procurou-se determinar os aspectos gerais da integração e do escopo na colaboração da autopeça e cada um de seus clientes. São analisados aspectos gerais uma vez que tais variáveis assumem conteúdos diferentes não apenas conforme o cliente, mas dependendo também do projeto em questão.

A Figura 1 apresenta na parte central a estrutura organizacional de desenvolvimento do fornecedor (esfera) rodeada das estruturas organizacionais de desenvolvimento de seus clientes (esferas em torno da esfera anterior), ligadas por figuras geométricas que representam colaborações no desenvolvimento de produto. Cada uma destas figuras é formada por setas (que representam as variáveis integração), áreas cinza-claro (escopo do fornecedor) e áreas cinza-escuro (escopo dos clientes). O objetivo do trabalho é portanto caracterizar a área "cinza-claro" e as "setas" para cada cliente. Em seguida, discute-se a influência na qualidade do projeto do produto.

As empresas foram visitadas no período compreendido entre 1996 e 1997. Cada visita compreendia uma entrevistas com o responsável pelo setor de desenvolvimento de produto do fornecedor, com engenheiros de projeto, e visitas às instalações fabris e à unidade de desenvolvimento de produto. 
Tabela 1 - Tipologia utilizada para a métrica do escopo.

\begin{tabular}{|l|l|}
\hline Tipo de Projeto de Desenvolv. & Descrição \\
\hline $\begin{array}{l}\text { Peças de Propriedade da } \\
\text { Autopeça }\end{array}$ & $\begin{array}{l}\text { São produtos totalmente desenvolvidos e testados pela empresa de } \\
\text { autopeça e vendidos às montadoras por catálogos e/ou assistência técnica, } \\
\text { onde a empresa de autopeça auxilia a montadora na escolha do modelo que } \\
\text { melhor se adapte às condições do seu produto (Ex.: baterias e pneus). }\end{array}$ \\
\hline Black box & $\begin{array}{l}\text { Neste tipo a montadora estabelece as metas de desempenho, detalhes da } \\
\text { interface, forma exterior e outros aspectos básicos e a empresa de autopeça } \\
\text { faz a engenharia detalhada da peça, podendo construir ou não o protótipo } \\
\text { (Ex.: sistemas de freios). }\end{array}$ \\
\hline $\begin{array}{l}\text { Peças de Controle Detalhado do } \\
\text { Cliente }\end{array}$ & $\begin{array}{l}\text { São projetos em que a montadora realiza o projeto detalhado da peça e a } \\
\text { autopeça desenvolve o processo, podendo construir ou não o protótipo } \\
\text { (Ex.: direção). }\end{array}$ \\
\hline $\begin{array}{l}\text { Adaptação de Peças de Controle } \\
\text { Detalhado do Cliente }\end{array}$ & $\begin{array}{l}\text { Idem ao anterior, mas a empresa de autopeça pode sugerir alterações ou, } \\
\text { mesmo a montadora, pode também requisitá-las (caso típico da } \\
\text { nacionalização de um produto). }\end{array}$ \\
\hline
\end{tabular}

Tabela 2 - Tipologia para métrica da integração.

\begin{tabular}{|c|c|c|c|}
\hline & Comunicação & Compatibilidade & Cooperação \\
\hline Estratégico & $\begin{array}{l}\text { Estruturas formais e intensidade } \\
\text { da comunicação entre a alta } \\
\text { administração do cliente e do } \\
\text { fornecedor (por exemplo: } \\
\text { reuniões, participação na } \\
\text { diretoria, etc.). }\end{array}$ & $\begin{array}{l}\text { Grau com que as estratégias das } \\
\text { empresas-clientes se } \\
\text { compatibilizam com as dos } \\
\text { fornecedores (por exemplo: } \\
\text { investimentos futuros em } \\
\text { tecnologia, processos, mercado, } \\
\text { etc.). }\end{array}$ & $\begin{array}{l}\text { Grau de cooperação na } \\
\text { elaboração do planejamento } \\
\text { estratégico. }\end{array}$ \\
\hline Tático & $\begin{array}{l}\text { Estruturas formais e intensidade } \\
\text { da comunicação entre a média } \\
\text { gerência para a elaboração dos } \\
\text { planos das atividades de } \\
\text { desenvolvimento realizadas } \\
\text { conjuntamente pelas empresas. } \\
\text { (comunicação sobre etapas, } \\
\text { planos e cronogramas). }\end{array}$ & $\begin{array}{l}\text { Grau de compatibilidade entre a } \\
\text { média gerência com relação ao } \\
\text { planejamento das etapas de } \\
\text { desenvolvimento (metas, } \\
\text { desenvolvimento de planos). }\end{array}$ & $\begin{array}{l}\text { Grau de cooperação entre a média } \\
\text { gerência do desenvolvimento de } \\
\text { produto da empresa-cliente e do } \\
\text { fornecedor (por exemplo, } \\
\text { confiança, compromisso e apoio } \\
\text { técnico). }\end{array}$ \\
\hline Operacional & $\begin{array}{l}\text { Estruturas formais e intensidade } \\
\text { da comunicação no } \\
\text { desenvolvimento das atividades } \\
\text { do desenvolvimento (reuniões de } \\
\text { apresentação formais do projeto, } \\
\text { mecanismos de comunicação de } \\
\text { problemas, dúvidas, etc.). }\end{array}$ & $\begin{array}{l}\text { Grau de compatibilidade nas } \\
\text { estruturas para operacionalização } \\
\text { das atividades conjuntas (normas } \\
\text { de engenharia e equipamentos } \\
\text { para teste, linguagem). }\end{array}$ & $\begin{array}{l}\text { Grau de cooperação nas } \\
\text { atividades de desenvolvimento } \\
\text { (por exemplo, confiança nas } \\
\text { informações trocadas durante as } \\
\text { atividades, cooperação na solução } \\
\text { de problemas, apoio técnico } \\
\text { como auxílio em laboratório, } \\
\text { etc.). }\end{array}$ \\
\hline Pessoal & $\begin{array}{l}\text { Intensidade da proximidade } \\
\text { pessoal entre os funcionários das } \\
\text { empresas (quantidade de contatos } \\
\text { informais e a liberdade para troca } \\
\text { de informações entre as pessoas). }\end{array}$ & $\begin{array}{l}\text { Compatibilidade entre as pessoas } \\
\text { das duas organizações (amizade, } \\
\text { inexistência de barreiras culturais, } \\
\text { inexistência de conflito de } \\
\text { interesses entre as pessoas, etc.). }\end{array}$ & $\begin{array}{l}\text { Cooperação entre as pessoas de } \\
\text { ambas as empresas (confiança } \\
\text { nos funcionários da outra } \\
\text { empresa, o compromisso entre as } \\
\text { pessoas). }\end{array}$ \\
\hline
\end{tabular}




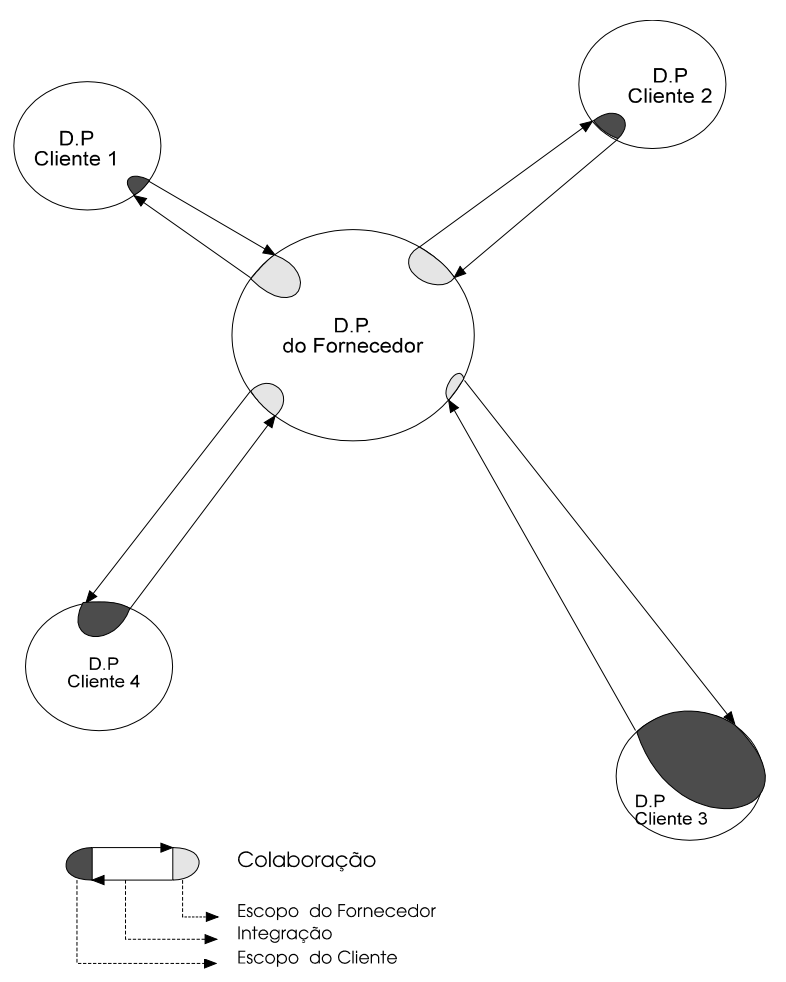

Figura 1 - Unidade de análise da pesquisa.

Os casos foram selecionados dentro da indústria automobilística brasileira porque esta indústria apresenta um nível alto de complexidade em termos da gestão dos seus processos de desenvolvimento de produto, tornando mais evidente as influências das práticas de gestão no desempenho desse processo. Além disso, foi e tem sido o berço das novas práticas na manufatura, aumentando a chance de analisar modelos mais evoluídos; é altamente internacionalizada tal que essas novas práticas tendem a ser rapidamente disseminadas das matrizes e mercados principais para as demais regiões produtoras; e é altamente competitiva, levando a um grande número de projetos de desenvolvimento em andamento (CLARK \& FUJIMOTO, 1991). Dois outros fatores tornam ainda mais importante realizar o estudo de caso nessa indústria: em primeiro lugar a prática de colaboração cliente-fornecedor no processo de desenvolvimento de produto nasceu aí, na indústria automobilística japonesa; e também porque, no Brasil, há indícios que a tendência em direção a colaboração cliente- fornecedor no desenvolvimento de produto já é uma realidade nessa indústria.

É importante notar que a pesquisa assim definida aborda a colaboração sob a ótica do fornecedor. Esta decisão, que implicou em não analisar a montadora, foi tomada diante das limitações de recurso e tempo. Decidiu-se pela visão do fornecedor por ser ele quem sente de forma mais clara os problemas devido à integração e aos fatores que a influenciam. Os fornecedores se relacionam com poucos clientes e sentem com mais riqueza de detalhes as dificuldades no detalhamento dos projetos e na fabricação dos produtos decorrentes do processo de desenvolvimento; ao contrário das empresasclientes (montadoras), que lidam com centenas de fornecedores e muitas vezes desconhecem pequenos problemas e detalhes do projeto que acabam se restringindo ao âmbito da empresafornecedora. No entanto, perde-se, com isso, a visão mais ampla, ou seja, a dos padrões de comportamento entre a empresa-cliente e o conjunto de seus fornecedores, particularizando-se o 
resultado. Entretanto esta restrição é coerente com o sentido exploratório ao qual o trabalho se destina.

\section{Descrição e Análise dos Resultados}

$\mathrm{N}^{2}$ a empresa A foram analisadas duas instalações de desenvolvimento de produto e realizadas duas entrevistas, uma em cada unidade. Na empresa B foi realizada uma visita. Para cada uma delas são apresentadas a caracterização da empresa, a caracterização de seu setor de desenvolvimento de produto, um histórico do relacionamento da empresa com cada um dos clientes, uma descrição do escopo do fornecedor e da integração, e uma descrição sobre o relacionamento entre estas duas variáveis com a qualidade do projeto do produto.

\subsection{Empresa A}

\subsubsection{Caracterização da Empresa A}

A empresa A tem seu capital controlado por um grupo inglês e atua no ramo de autopeças para acabamento. Sua linha de produtos é extensa, variando de volantes, painéis até carpetes e é produzida em diversas unidades espalhadas pelas regiões de São Paulo e Minas Gerais. Cada unidade tem autonomia própria se reportando diretamente à diretoria do grupo. Porém, no caso específico do desenvolvimento de produto, este é realizado na unidade principal que fica no interior de São Paulo e é responsável por este processo em todas as demais empresas. Nas demais unidades há equipes de desenvolvimento que acompanham o desenvolvimento e são responsáveis pelas etapas finais de try-out (testes do ferramental) e aprovação para a produção.

Foram analisadas a matriz e uma das unidades menores, para acompanhar todo o processo de desenvolvimento de produto. A unidade maior da empresa $\mathrm{A}$, onde ocorre a maior parcela do desenvolvimento conta com aproximadamente 1600 funcionários e produz diversas linhas de produtos, tais como painéis, volantes, pára-choques, saias, apoios de cabeça, apoios para braço, conjunto porta-luvas, lateral da porta, etc. As linhas de produto mais importantes para esta unidade são as de pára-choques e painéis. A unidade menor da empresa se localiza no interior de Minas Gerais, conta atualmente com cerca de 400 funcionários e produz as seguintes linhas de produto: laterais moldadas; laterais planas; portapacote; consoles; quebra-sol; e carpetes e ovatas.

A empresa A atua nos mercados de Equipamento Original (vendendo diretamente às montadoras), Autopeças (fornecendo produtos para outras empresas de autopeças) e externo (exportando produtos). Ela não vende diretamente para distribuidores, no mercado de reposição, mas seus produtos atingem esse mercado por meio das montadoras, como peça original.

\subsubsection{O Desenvolvimento de Produto da Empresa A}

A empresa desenvolve projetos de novos produtos dos tipos Black Box, Partes de Controle Detalhado do Cliente e Adaptações de Partes de Controle Detalhado do Cliente. A maioria dos projetos são desses dois últimos tipos. A tendência é de aumento dos tipos de projetos Black Box e Adaptações de Partes de Controle do Cliente, e a diminuição dos projetos do tipo Partes de Controle Detalhado do Cliente. Em todos eles a empresa é responsável pela confecção dos protótipos.

A organização do desenvolvimento de produto da empresa A segue a filosofia de times. $\mathrm{Na}$ unidade principal a Engenharia conta com aproximadamente 45 funcionários que são alocados em times separados por tipos de produtos, que são: cockpit (painel, volante e console), acabamento interno (tais como lateral da porta, quebra-sol) e acabamento externo (pára-choque, minissaia e grade).

Existem procedimentos de Garantia da Qualidade para o desenvolvimento de produto, segundo o padrão ISO 9001/QS9000, que determinam as fases e os documentos que devem ser elaborados durante o desenvolvimento. Porém, durante este 
processo, as atividades são guiadas de acordo com as necessidades do projeto específico que está em execução, podendo apresentar variações.

Durante o desenvolvimento são realizados aproximadamente 15 tipos de testes diferentes, que incluem durabilidade, confiabilidade, estanqueidade e outros. Nos projetos da unidade menor são realizados quatro tipos principais de testes, os mesmos para todos os clientes. As empresas-clientes se responsabilizam pelos testes de campo e ajuste (Matching), os quais são acompanhados pelos técnicos da empresa A, sendo que estes últimos muitas vezes realizam estes testes internamente, antes do cliente, a partir de pedaços da carroceria do produto final cedidos para este fim.

\subsubsection{Histórico do Relacionamento com Clientes}

O CLIENTE 1 é um dos de relacionamento mais estreito com a empresa A. Para a unidade menor ele é o mais antigo e o que representa o maior volume de vendas e de faturamento, aproximadamente $50 \%$ do volume de vendas do produto principal (porta-pacote) e cerca de $60 \%$ do faturamento desta unidade é devido a este cliente, para o qual são fornecidos produtos de todas as linhas da empresa.

Há um relacionamento intenso do CLIENTE 1 com a empresa A, a qual está construindo uma nova fábrica ao lado da unidade de produção dessa montadora, em troca do contrato de fornecimento exclusivo para um determinado produto a ser montado num novo modelo do cliente. A empresa A mantém, dentro da unidade de produção do CLIENTE 1, um galpão de armazenagem construído especificamente para atendê-lo, onde são armazenadas as peças para a entrega. Além disso, na unidade menor analisada da empresa A, há uma linha de produção de laterais planas cujos equipamentos foram cedidos em regime de comodato pela CLIENTE 1, em troca de exclusividade no fornecimento dessa peça.

Para a unidade principal todos os demais clientes-montadores nacionais têm um vínculo antigo. Já na unidade menor o CLIENTE 1 é o mais importante, o CLIENTE 2 é o segundo em ordem de importância com a autopeça fornecendo a ele todos os tipos de produtos, com exceção da linha de Laterais Planas, há aproximadamente 15 anos, seguido pelo CLIENTE 3 para o qual fornece há aproximadamente 11 anos, e atualmente entrega apenas porta-pacotes (esta unidade não fornece para o CLIENTE 4).

\subsubsection{Escopo do Fornecedor}

No caso do produto painel, da unidade principal, os tipos de projeto mais freqüentes para o CLIENTE 1 e CLIENTE 4 são Black Box e Adaptações de Peças de Controle Detalhado do Cliente. Para as empresas CLIENTE 2 e CLIENTE 3 o tipo mais freqüente é o de Peças de Controle Detalhado do Cliente.

Quanto ao porta-pacote produzido pela unidade menor, para o CLIENTE 1, em sua maioria, os projetos são adaptações de projetos cedidos pelo cliente, nos quais o cliente apresenta o projeto detalhado e a empresa A se encarrega do desenvolvimento do processo de fabricação e dos protótipos, estando aberta para a proposição de alterações (Adaptações de Partes de Controle Detalhado do Cliente). Foi também desenvolvido um projeto do tipo Black Box com a colaboração da empresa italiana com a qual a empresa mantém um contrato de aquisição de tecnologia: esta última participou de todo o desenvolvimento do projeto do CLIENTE 1, com acompanhamento pela empresa A que participou do desenvolvimento do processo. Para o CLIENTE 2 foram desenvolvidos projetos de todos os tipos, Black Box, Partes de Controle Detalhado do Cliente, e Adaptações de Partes de Controle Detalhado do Cliente. No entanto, o tipo mais comum é o último, Adaptações de Partes de Controle Detalhado.

Os tipos de projeto já desenvolvidos para o CLIENTE 3 são os Black Box e Adaptação de Partes de Controle Detalhado do Cliente, sendo o último mais freqüente. 


\subsubsection{Integração}

\section{Integração Estratégica}

A empresa A procura manter uma relação estreita entre suas diretorias e todos os seus clientes, indistintamente, buscando desenvolver ações e negociações nas esferas mais altas da empresa.

Deve-se destacar, no entanto, o fato da integração estratégica parecer mais desenvolvida com o CLIENTE 1, pois a diretoria da empresa A mantém uma relação direta com os membros da alta administração desse cliente e há acordos concretos entre este cliente e a empresa assinados nesse nível gerencial (como é o caso recente da nova unidade de produção, a ser instalada próxima ao cliente e específica para a fabricação de um produto de uma das empresas do grupo em troca do monopólio do fornecimento dessa peça para um dos modelos do cliente), e há investimentos específicos por parte da autopeça na transação com esta montadora. Apesar disso, nem todos os projetos são tratados nesse nível e não há compromissos formais, estando a empresa A sujeita, inclusive, a ameaças (típicas dos relacionamentos de saída) e sendo obrigada, na maioria das vezes, a disputar concorrências normais.

\section{Integração Tática}

Os mecanismos formais de integração tática, tais como reuniões periódicas, cronogramas e procedimentos são praticamente os mesmos para todos os clientes. As datas e prazos são em todos os casos especificados pelo cliente, sendo sua obrigação cumpri-los. Existem datas que devem ser obrigatoriamente respeitadas: entrega da amostra, lote piloto e início da produção. As demais podem ser eventualmente negociadas caso haja atrasos ou adiantamentos.

Segundo um dos entrevistados, o CLIENTE 1 se destacaria neste item por possibilitar uma maior liberdade em termos de sugestão de alterações nos planos e maior transparência de custos, devido a uma planilha mais detalhada que a dos demais clientes. Isto torna mais importante a necessidade de se realizar um projeto de alta qualidade, dado que as alterações posteriores à homologação são difíceis por serem tratadas diretamente com o departamento de compras do cliente. Assim, quando um projeto apresenta algum problema, as alterações são acompanhadas de solicitações, por parte do departamento de compras do cliente, de reduções no preço.

\section{Integração Operacional}

Em termos operacionais, que diz respeito à execução e planejamento das atividades específicas de desenvolvimento, os mecanismos formais de integração são reuniões periódicas com os clientes e por meios de comunicação comuns, sendo os de maior freqüência o FAX e o telefone. A empresa está planejando adotar a prática de engenheiros residentes, mas ainda não os possui em nenhum cliente. Nos casos onde o escopo do projeto é maior, os engenheiros da empresa visitam intensamente os clientes, geralmente com freqüências de duas visitas por semana.

Em termos de compatibilidade dos recursos técnicos, no nível operacional, não há qualquer diferença entre as montadoras, sendo que a empresa possui internamente todos os meios necessários para desenvolver o projeto e realizar os testes, sendo empregados os mesmos independentemente do cliente.

Apesar da grande homogeneidade da integração neste nível, segundo o entrevistado, há algumas diferenças entre os clientes. $\mathrm{O}$ acesso ao CLIENTE 1 é mais fácil. Entre os três, o CLIENTE 2 é o de mais fácil "operacionalização" do projeto, permitindo acesso fácil e regular na empresa-cliente e respostas rápidas às solicitações efetuadas durante o projeto. No caso do CLIENTE 3 o acesso é fácil e freqüente, com menor clareza de informações e respostas mais lentas em comparação com as demais.

\section{Integração Pessoal}

Para todos os clientes o grau de integração pessoal varia muito dependendo do projeto e é de suma importância para que se tenha êxito no 
desenvolvimento. É preciso manter boas relações pessoais para facilitar o fluxo de informações. Este tipo de integração ajuda sobremaneira na agilização das tarefas e prontidão das informações requisitadas aos clientes. Além disso, uma boa integração pessoal é fundamental para a resolução de problemas que surgem durante o projeto.

Ajuda muito, além disso, conhecer os procedimentos do cliente e seus funcionários do setor de desenvolvimento, principalmente porque, dessa maneira, é possível descobrir a pessoa certa para tratar do assunto em questão, economizando tempo.

A integração pessoal seria, então, necessária mas não suficiente. Onde há problemas pessoais entre os membros da equipe do fornecedor e do cliente o projeto é comprometido, porém, uma boa integração pessoal, sozinha, não garante um bom resultado em termos da qualidade do projeto do produto. Em determinados casos, em que este tipo de problema é muito grande, a empresa A pode até mesmo substituir o membro da sua equipe de projeto.

A Tabela 3 apresenta um quadro comparativo das características do escopo e da integração para a colaboração no desenvolvimento de produto da empresa A e cada um dos seus clientes.

\subsubsection{Inter-relações entre a Integração, Escopo e a Qualidade do Projeto do Produto}

Quanto ao escopo, como ele apresentou poucas variações entre as colaborações no desenvolvimento de produto com os diferentes clientes, não foi possível analisar profundamente a sua implicação na qualidade do projeto do produto para este caso. Segundo um dos entrevistados, o escopo influenciaria principalmente nos parâmetros da qualidade do produto ligados com a conformidade, pois o aumento do escopo permitiria projetar produtos mais adequados aos seus meios de produção (ferramental, equipamentos, etc.), ganhando em manufaturabilidade.

Em termos de impacto na qualidade do projeto do produto, para este caso, os níveis de integração mais importantes seriam a integração tática e a operacional.

A tática influenciaria somente no aspecto da possibilidade de uma margem de manobra nos planos impostos pelas montadoras, já que os demais não se diferenciaram entre os diversos clientes. A possibilidade maior de influir na definição do prazos estabelecidos no planejamento do projeto permite ao fornecedor balancear e programar melhor o trabalho da sua equipe de engenharia, incorporando neste plano suas restrições internas de tempo e prazo.

A integração operacional seria de fundamental importância pois define o grau de comunicação entre as equipes de projeto. Já a integração pessoal influenciaria indiretamente a qualidade do projeto do produto por facilitar e agilizar a resolução dos problemas que surgem durante o desenvolvimento.

\subsection{Empresa B}

\subsubsection{Caracterização da Empresa B}

A empresa B é hoje uma multinacional pertencente a um grande grupo americano que, além do mercado de autopeças, tem expressiva participação em outros mercados no âmbito mundial. Essa unidade foi adquirida por esse grupo em 1973, de uma empresa de capital nacional, e passou a ser a única empresa de autopeças do grupo especializada na fabricação de rodas de aço.

A linha de produto de rodas de aço para carros de passeio é praticamente a única linha de produtos da empresa, depois que esta recentemente decidiu interromper a produção de rodas para tratores e caminhões leves, se concentrando no mercado de automóveis. Além disso, o mercado de reposição é praticamente inexistente, pois corresponde a uma porcentagem mínima em relação à quantidade de produtos destinado ao mercado de equipamento original.

Ela é líder nesse segmento e tem apenas um concorrente no país, o qual detém uma parcela pequena do mercado. Além disso, tem uma 
Tabela 3 - Comparativo da integração e escopo da empresa A e seus clientes.

\begin{tabular}{|c|c|c|c|c|}
\hline & $\begin{array}{l}\text { Integração } \\
\text { Estratégica }\end{array}$ & Integração Tática & $\begin{array}{l}\text { Integração } \\
\text { Operacional }\end{array}$ & Escopo \\
\hline CLIENTE 1 & $\begin{array}{l}\text { Há interesse do } \\
\text { fornecedor em ações } \\
\text { neste nível; } \\
\text { Há ações e } \\
\text { negociações concretas } \\
\text { neste nível; }\end{array}$ & $\begin{array}{l}\text { Cliente impõe } \\
\text { cronogramas e planos; } \\
\text { Há maior liberdade no } \\
\text { detalhamento dos } \\
\text { planos; e } \\
\text { Planilha de Custos é } \\
\text { mais detalhada; }\end{array}$ & $\begin{array}{l}\text { Mecanismos formais } \\
\text { iguais (reuniões, fax e } \\
\text { telefone); } \\
\text { Acesso um pouco } \\
\text { mais fácil ao cliente; }\end{array}$ & $\begin{array}{l}\text { Black Box; } \\
\text { Adaptações de Partes } \\
\text { de Controle } \\
\text { Detalhado. }\end{array}$ \\
\hline CLIENTE 2 & $\begin{array}{l}\text { Há interesse do } \\
\text { fornecedor em ações } \\
\text { neste nível; }\end{array}$ & $\begin{array}{l}\text { Cliente impõe } \\
\text { cronogramas e planos; }\end{array}$ & $\begin{array}{l}\text { Mecanismos formais } \\
\text { iguais (reuniões, fax e } \\
\text { telefone); } \\
\text { Acesso um pouco } \\
\text { mais fácil ao cliente; } \\
\text { Maior presteza e } \\
\text { agilidade }\end{array}$ & $\begin{array}{l}\text { Controle Detalhado } \\
\text { da Montadora }\end{array}$ \\
\hline CLIENTE 3 & $\begin{array}{l}\text { Há interesse do } \\
\text { fornecedor em ações } \\
\text { neste nível; }\end{array}$ & $\begin{array}{l}\text { Cliente impõe } \\
\text { cronogramas e planos; }\end{array}$ & $\begin{array}{l}\text { Mecanismos formais } \\
\text { iguais (reuniões, fax e } \\
\text { telefone); }\end{array}$ & $\begin{array}{l}\text { Controle Detalhado } \\
\text { da Montadora }\end{array}$ \\
\hline CLIENTE 4 & $\begin{array}{l}\text { Há interesse do } \\
\text { fornecedor em ações } \\
\text { neste nível; }\end{array}$ & $\begin{array}{l}\text { Cliente impõe } \\
\text { cronogramas e planos; }\end{array}$ & $\begin{array}{l}\text { Mecanismos formais } \\
\text { iguais (reuniões, fax e } \\
\text { telefone); }\end{array}$ & $\begin{array}{l}\text { Black Box; } \\
\text { Adaptações de Partes } \\
\text { de Controle } \\
\text { Detalhado. }\end{array}$ \\
\hline
\end{tabular}

atuação forte internacionalmente, e, por ser a única empresa desse grupo a manufaturar este produto, serve de base para as operações do grupo no mundo inteiro nesse segmento do mercado de autopeças. Cerca de 55\% do total de vendas de equipamento original é destinado ao mercado externo, principalmente direcionados para um mesmo cliente-montadora de automóveis de origem americana.

\subsubsection{O Desenvolvimento de Produto da Empresa B}

A empresa B considera o desenvolvimento de produto como um serviço a ser oferecido aos seus clientes. Há casos em que a empresa desenvolve um produto para um determinado cliente que, por problemas de escala, ela não tem interesse em fabricar, sendo este seu projeto passado para o concorrente por intermédio do cliente.
Em seu departamento de engenharia são elaborados muitos estudos e análises iniciais, sendo que a maioria acaba não se concretizando em um projeto, seja por alterações nos planos dos clientes (fim de projeto, aproveitamento de partes, etc.) e/ou por perder a concorrência para outra empresa.

Devido às características do produto, o processo de desenvolvimento é bastante regular passando sempre pelas mesmas fases, ou seja, sendo mais estruturado se comparado com a empresa A. Os procedimentos que a empresa possui implantados em seu setor de desenvolvimento, de acordo com a certificação QS 9000, são rigorosamente seguidos durante os projetos. Ele inicia com as seguintes etapas gerais: análise crítica de contrato, análise crítica técnica, aprovação pelo responsável da empresa e, se confirmada, parte-se para cotação e apresentação ao cliente. Se aprovado pelo cliente, será emitido 
um pedido de compras dentro da empresa $\mathrm{B}$ e serão definidos prazos de entregas das amostras. É feito então um cronograma do projeto e iniciase o projeto do produto, depois o projeto do processo, o projeto do ferramental, e, por último, o try out: fase em que são realizados ajustes de ferramentas e estudos de capacidade do processo. São realizados aproximadamente 50 testes diferentes nesse produto, os mesmos para todos os clientes.

Como o produto é bastante específico, essas fases são, além de constantes, realizadas de maneira seqüencial, sem muita simultaneidade e os projetos não se diferenciam entre novos $\mathrm{e}$ antigos. A estrutura de desenvolvimento de produto da empresa é constituída por 15 funcionários organizados em um sistema matricial, em que todos têm suas funções específicas e são alocados de acordo com a necessidade nos times de projeto.

\subsubsection{Histórico do Relacionamento com Clientes}

A Empresa B tem trabalhado com todos os clientes praticamente desde a instalação destes no país. Ela começou a produzir no início da implantação da indústria automobilística brasileira e, aproveitando o movimento de nacionalização das peças desta indústria, entrou no mercado de equipamento original, mantendo-se, desde então, como fornecedor de todas as montadoras nacionais.

A porcentagem do mercado dos clientes para esse produto sob domínio da empresa são: CLIENTE $1, \quad 100 \%$; CLIENTE 2, 40\%; CLIENTE $3, \quad 70 \%$; CLIENTE $4,50 \%$; CLIENTE 5, 85\% (Montadora Americana).

Não há casos de investimentos específicos com clientes a não ser o CLIENTE 5, o qual exige a entrega just-in-time de produtos e, por encontrar-se instalado em outro país (os EUA), gerou a necessidade da empresa instalar uma unidade, localizada nos Estados Unidos, especificamente para estocar os produtos e fornecê-los em regime JIT.

\subsubsection{Escopo do Fornecedor}

Os projetos de desenvolvimento deste produto podem ser do tipo "Black Box" e do tipo "Partes de Controle Detalhado do Cliente".

Nos do primeiro tipo, o cliente entrega apenas um release da peça contendo algumas características tais como peso, custo, carga sobre cada roda, se utilizará calota ou não, distâncias do freio e dimensionamento da furação da roda, podendo acompanhar ou não o design do estilo que pode ser proposto também pela autopeça. Caso o projeto preveja a calota, o cliente pode solicitar à empresa que elabore um desenho que otimize o desempenho em termos de resistência, custo e peso.

Há também projetos em que o cliente envia um desenho detalhado da peça solicitando o orçamento do mesmo. É política da empresa, nestes casos, elaborar sempre dois estudos, um dos quais orçando a peça tal qual o cliente a solicitou e outra com pequenas alterações elaboradas pelo seu setor de desenvolvimento, as quais manteriam as características funcionais $\mathrm{e}$ estéticas da peça, porém com melhorias no desempenho e/ou custo.

\subsubsection{Integração}

\section{Integração Estratégica}

Não há diferença neste nível de integração entre cada cliente, pois: todos os clientes são considerados importantes pela empresa; o fato de fazer parte de um grupo internacional dá acesso a um envolvimento com a alta administração de todos os grandes produtores mundiais de automóveis; e o planejamento estratégico da empresa (com horizonte de 5 anos) é realizado separadamente para cada cliente. Parece haver, no entanto, uma afinidade maior com o CLIENTE 5 no exterior e com o CLIENTE 1 no Brasil.

\section{Integração Tática}

Nos projetos de desenvolvimento, a empresa estudada segue sempre os planos e prazos 
traçados pelos clientes e considera que hoje há bastante confiança mútua entre eles. A única diferenciação entre eles seria no quesito liberdade para a sugestão de alterações e discussão dos prazos, nos quais as empresas CLIENTE 1 , CLIENTE 3 e CLIENTE 4 estariam num mesmo patamar, no qual há uma maior liberdade em relação ao CLIENTE 2.

\section{Integração Operacional}

Todos os clientes apresentam atualmente acesso fácil ao seu departamento de desenvolvimento de produto, freqüência de contato suficiente e poucos problemas de clareza nas informações. A diferença apresenta-se em termos da rapidez e prontidão das respostas, aparecendo em primeiro lugar, como melhor neste quesito, a empresa CLIENTE 1 seguida pela CLIENTE 3 e, juntas em terceiro lugar, a CLIENTE 4 e CLIENTE 2. A melhor empresa para se trabalhar, operacionalmente, é a CLIENTE 5, pois o desenvolvimento mantém toda a responsabilidade inclusive por negociar o preço dos produtos, possibilitando bastante autonomia para o fornecedor desenvolver os projetos. Neste cliente o papel de compras é o de administradores de preço, depois que o produto entrar em produção.

Um engenheiro da empresa declarou que algumas vezes acontecem problemas de coordenação entre os departamentos de desenvolvimento, estilo e compras do cliente, o que chega a gerar até a necessidade de três estudos alternativos para um mesmo projeto. Já aconteceu do departamento de estilo do cliente aprovar uma proposta que foi posteriormente recusada pelo pessoal de desenvolvimento (preocupados com o peso) e o mesmo com compras (recusado pelo preço). Segundo ele, isto dificulta e encarece o projeto.

\section{Integração Pessoal}

Em termos de integração pessoal entre os clientes e a empresa, a de menor integração entre as montadoras brasileiras, segundo o entrevistado, é a CLIENTE 2, onde há o pessoal em que o desenvolvimento de produto da empresa tem a menor afinidade. É importante manter contato constante com o cliente porque informações não oficiais sobre determinados projetos são comumente liberadas previamente pelo pessoal de desenvolvimento da montadora, de forma que a empresa B pode antecipar seus estudos de viabilidade e dar início ao desenvolvimento, correndo, claro, o risco de perder este trabalho.

$\mathrm{Na}$ Tabela 4 resume-se os resultados das variáveis escopo e integração para o caso estudado.

\subsubsection{Inter-relações entre Integração, Escopo e a Qualidade do Projeto do Produto}

$\mathrm{Na}$ opinião do entrevistado, estar bem integrado ao cliente é fundamental para o desempenho do projeto de desenvolvimento e influenciaria na qualidade do produto e demais parâmetros de desempenho desse processo. $\mathrm{O}$ entrevistado relatou um caso em que o pessoal de desenvolvimento de um cliente no Brasil solicitou o desenvolvimento de uma peça, a partir do projeto pronto, e que a empresa, ao realizar o estudo, advertiu que o projeto estava com problemas. A montadora brasileira exigiu a continuidade do projeto conforme havia sido especificado e o problema mais tarde apareceu. No contato com a matriz da montadora (responsável pela elaboração daquele projeto) percebeu-se que havia informações que a filial dessa empresa no Brasil desconhecia, as quais induziram ao erro. Isto poderia ter sido evitado caso a montadora nacional interagisse mais com o fornecedor, assumindo uma atitude colaborativa, e levasse em consideração os avisos do pessoal de desenvolvimento do mesmo, confiando em sua capacidade técnica.

Para o entrevistado, os principais tipos de integração com os clientes, em termos de influência na qualidade do projeto do produto, são a integração tática e a pessoal. A tática principalmente pelo cumprimento dos prazos e da capacidade de responder rapidamente e com prontidão aos problemas que surgem, e a pessoal 
Tabela 4 - Comparativo da integração e escopo da empresa B e seus clientes.

\begin{tabular}{|c|c|c|c|c|c|}
\hline & $\begin{array}{l}\text { Integração } \\
\text { Estratégica }\end{array}$ & $\begin{array}{c}\text { Integração } \\
\text { Tática }\end{array}$ & $\begin{array}{c}\text { Integração } \\
\text { Operacional }\end{array}$ & $\begin{array}{c}\text { Integração } \\
\text { Pessoal }\end{array}$ & Escopo \\
\hline CLIENTE 1 & $\begin{array}{l}\text { Contatos com a } \\
\text { matriz da } \\
\text { montadora } \\
\text { brasileira; } \\
\text { Plano Estratégico } \\
\text { (5 anos). }\end{array}$ & $\begin{array}{l}\text { Cliente impõe } \\
\text { cronogramas e } \\
\text { planos; } \\
\text { Maior liberdade } \\
\text { nos planos; }\end{array}$ & $\begin{array}{l}\text { Acesso fácil; } \\
\text { Freqüência de } \\
\text { contatos } \\
\text { suficiente; } \\
\text { Maior rapidez e } \\
\text { prontidão nas } \\
\text { respostas entre } \\
\text { todas. }\end{array}$ & Suficiente & $\begin{array}{l}\text { Black Box; } \\
\text { Adaptações de } \\
\text { Partes de } \\
\text { Controle } \\
\text { Detalhado. }\end{array}$ \\
\hline CLIENTE 2 & $\begin{array}{l}\text { Contatos com a } \\
\text { matriz da } \\
\text { montadora } \\
\text { brasileira; } \\
\text { Plano Estratégico } \\
\text { (5 anos). }\end{array}$ & $\begin{array}{l}\text { Cliente impõe } \\
\text { cronogramas e } \\
\text { planos; }\end{array}$ & $\begin{array}{l}\text { Acesso fácil; } \\
\text { Freqüência de } \\
\text { contatos } \\
\text { suficiente; } \\
\text { Menor rapidez e } \\
\text { prontidão. }\end{array}$ & Menor afinidade & $\begin{array}{l}\text { Black Box; } \\
\text { Adaptações de } \\
\text { Partes de } \\
\text { Controle } \\
\text { Detalhado. }\end{array}$ \\
\hline CLIENTE 3 & $\begin{array}{l}\text { Contatos com a } \\
\text { matriz da } \\
\text { montadora } \\
\text { brasileira; } \\
\text { Plano Estratégico } \\
\text { (5 anos). }\end{array}$ & $\begin{array}{l}\text { Cliente impõe } \\
\text { cronogramas e } \\
\text { planos; } \\
\text { Maior liberdade } \\
\text { nos planos; }\end{array}$ & $\begin{array}{l}\text { Acesso fácil; } \\
\text { Freqüência de } \\
\text { contatos } \\
\text { suficiente; } \\
\text { Rapidez e } \\
\text { prontidão. }\end{array}$ & Suficiente & $\begin{array}{l}\text { Adaptações de } \\
\text { Partes de } \\
\text { Controle } \\
\text { Detalhado. }\end{array}$ \\
\hline CLIENTE 4 & $\begin{array}{l}\text { Contatos com a } \\
\text { matriz da } \\
\text { montadora } \\
\text { brasileira; } \\
\text { Plano Estratégico } \\
\text { (5 anos). }\end{array}$ & $\begin{array}{l}\text { Cliente impõe } \\
\text { cronogramas e } \\
\text { planos; } \\
\text { Maior liberdade } \\
\text { nos planos; }\end{array}$ & $\begin{array}{l}\text { Acesso fácil; } \\
\text { Freqüência de } \\
\text { contatos } \\
\text { suficiente; } \\
\text { Menor rapidez e } \\
\text { prontidão. }\end{array}$ & Suficiente & $\begin{array}{l}\text { Adaptações de } \\
\text { Partes de } \\
\text { Controle } \\
\text { Detalhado }\end{array}$ \\
\hline CLIENTE 5 & $\begin{array}{l}\text { Contatos com a } \\
\text { matriz da } \\
\text { montadora; } \\
\text { Plano Estratégico } \\
\text { (5 anos). }\end{array}$ & $\begin{array}{l}\text { Cliente impõe } \\
\text { cronogramas e } \\
\text { planos; } \\
\text { Maior liberdade } \\
\text { nos planos; }\end{array}$ & $\begin{array}{l}\text { Acesso fácil; } \\
\text { Freqüência de } \\
\text { contatos; } \\
\text { Maior auto- } \\
\text { suficiência do } \\
\text { DP do cliente. }\end{array}$ & Suficiente & $\begin{array}{l}\text { Adaptações de } \\
\text { Partes de } \\
\text { Controle } \\
\text { Detalhado. }\end{array}$ \\
\hline
\end{tabular}

para que se consiga rapidamente as informações necessárias à confecção do projeto, com clareza e objetividade.

\section{Conclusão}

$\mathrm{Q}_{\mathrm{n}}^{\mathrm{u}}$ uanto a integração, os casos estudados mostram que a dimensão dessa variável referente aos mecanismos formais de informação (nos níveis Estratégico, Tático e Operacional) não se diferenciam de uma empresa fornecedora com relação aos vários clientes. Isso se deve a práticas de relacionamento comuns no setor. Mesmo que com diferentes graus entre as diferentes montadoras, todas elas parecem adotar engenheiros residentes, sistemas de cotação de preços parecidos, nível de transparência de custos (adoção de planilhas de custo) e acesso à 
empresa fornecedora dentro de sua unidade de desenvolvimento.

Fica evidente também para estes casos, que tais práticas não são suficientes para garantir a integração necessária para o desenvolvimento do produto, daí a importância, relatada nas duas empresas, de se manter uma alta integração pessoal, a qual em ambos os casos foi considerada uma das dimensões mais importantes. Ela seria uma dimensão importante em termos de aquisição das informações e resolução de problemas entre as empresas-membros da colaboração;

A integração estratégica é outro ponto importante para os casos estudados, mas não em termos de influência na qualidade do projeto do produto. Ela mostra-se fundamental, isto sim, para se desenvolver novos negócios, ou seja, ganhar o direito de fornecimento de novos produtos.

Em termos de integração tática esta variável não se diferenciou entre os clientes em nenhum dos dois casos estudados, pois há uma divisão do trabalho de planejamento e elaboração dos cronogramas comuns nas colaborações analisadas entre cliente-fornecedor no desenvolvimento de produto: ambos ficam a cargo do cliente, cabendo ao fornecedor se adequar aos prazos. Foi citado como importante, apenas, a existência de uma margem de flexibilidade nos planos das montadoras, para que se possa adequar os prazos das atividades de desenvolvimento do fornecedor, e que o planejamento não sofra alterações abruptas.

A integração apresenta um impacto importante no fluxo de informações e na flexibilidade da condução das atividades de desenvolvimento. Assim, quanto maior a integração mais a empresa consegue obter informações, tirar dúvidas, dar sugestões e atingir os prazos (por conseguir propor metas mais realistas para as suas atividades). $\mathrm{O}$ aumento do fluxo de informações poderia, então, impactar em termos de melhora na qualidade do projeto do produto.

Com relação ao escopo, não houve evidências sobre seu efeito na qualidade do projeto do produto. Porém, os dois casos ilustram formas com que o escopo pode afetar a qualidade do projeto do produto: o da empresa $\mathrm{B}$, que com maior responsabilidade e conhecimento do projeto é capaz de apresentar um produto de melhor desempenho em termos da característica funcional intrínseca, por meio de um estudo detalhado, utilizando elementos finitos, para compatibilizar o design da peça com o seu desempenho funcional; e o da empresa A, na qual o aumento do escopo do projeto possibilita tornar o produto mais adequado aos seus meios de produção aumentando a qualidade na dimensão de conformidade do produto, ou seja, a manufaturabilidade.

Uma conclusão geral, que se apresenta nesta pesquisa, é que os diversos clientes das empresas analisadas possuem mecanismos formais de integração no desenvolvimento de produto (nos níveis tático e operacional), em termos gerais, homogêneos comparando-se para um mesmo fornecedor. Assim, não há grandes diferenças interclientes na estrutura que suporta o projeto em conjunto. Além disso, percebe-se que, para os casos analisados, as dificuldades e necessidades extras que surgem durante o processo de desenvolvimento de produto são, muitas vezes, tratadas fora do âmbito desta estrutura que mantém a integração entre as empresas, dando à dimensão integração pessoal entre os membros das equipes um papel importante em termos de desempenho em qualidade nos casos estudados.

\section{Referências Bibliográficas}

ACHROL, R.S. et al.: Designing successful transorganizational marketing alliances. Cambridge, Marketing Science Institute. (Report n. 90-118), 1990.
AMARAL, D.C.: Colaboração cliente-fornecedor no desenvolvimento de produto: integração, escopo e qualidade do projeto do produto. São Carlos. 209p. Dissertação (Mestrado) - Universidade Federal de São Carlos, 1997. 
AMARAL, D.C.; TOLEDO, J.C. \& TAHARA, C.S.: "Modelo para a avaliação da integração na colaboração entre empresas". In: Encontro Nacional de Engenharia de Produção, n.28, 1998. Anais. Niterói-RJ, Associação Brasileira de Engenharia de Produção, 1998.

BIDAULT, F.; DESPRES, C. \& BUTLER, C.: "New product development and erarly supplier involvement (ESI): the drivers of ESI adoption." International journal of technology management, v.15, n.1/2, p.49-69, 1998.

BROWN, S.L. \& EISENHARDT, K.M.: "Product development: past research, present findings, and future directions." Academy of Management Review, v.20, n.2, p.343-378, Apr., 1995.

CERVO, A. \& BERVIAN, P.A.: Metodologia cientifica. 3.ed. São Paulo, MacGraw-Hill do Brasil, 1983.

CLARK, K.B.: "Project scope and project performance: the effect of parts strategy and supplier involvement on product development." Management Science, v.35, n.10, p.1247-1263, Oct., 1989.

CLARK, K.B. \& FUJIMOTO, T.: Product develop ment performance: strategy, organization and management in the world auto industry. Boston, Harvard Business School, 1991.

HARTLEY, J.L.; ZIRGER, B.J. \& KAMATH, R.R.: "Managing the buyer - supplier interface for ontime performance in product development." Journal of Operations Management, v.15, n.1, p.57-70, 1997.

HARTLEY, J.L.; MEREDITH, J.R.; McCUTCHEON, D. \& KAMATH, R.R.: "Supplier's contributions to product development: an exploratory study." IEEE Transactionson Engineering Management, v.44, n.3, p.238-267, Aug, 1997.
HOLANDA, A.B.: Dicionário Aurélio básico da língua portuguesa. Rio de Janeiro, Nova Fronteira, 1988.

IMAI, K.; NONAKA, I. \& TAKEUSHI, H.: "Managing the new product development process: how japanese companies learn and unlearn." In: CLARK, K.B.; HAYES, R. \& LORENZ, C. The uneasy alliance. Boston-Mass, Harvard Business School Press, p.533-561, 1985.

LAMMING, R.: Beyond partnership: strategies for innovation and lean supply. United Kingdon, Prentice-Hall, 1993.

LIKER, J.K.; KAMATH, R.R.; WASTI, S.N. \& NAGAMCHI: "Supplier involvement in automotive component design: are there really large US Japan differences?" Research Policy, v.25, n.1, p.59-89, Jan, 1996.

LITTLER, D.; LEVERICK, F. \& BRUCE, M.: "Factors affecting the process of collaborative product development: a study of UK manufacturers of information and communications technology products." Journal of Product Innovation Management, v.12, n.3, p.16-32, 1995.

NISHIGUSHI, T.: Strategic industrial sourcing: the japanese advantage. New York, Oxford University Press, 1994.

RAGATZ, G.L.; HANDFIELD, R.B. \& SCANNELL, T.V.: "Sucess factors for integrating suppliers into new product development." Journal of Product Innovation Management, v.14, n.2, p.190-202, 1997.

RICHARDSON, R.J.: Pesquisa Social: métodos e técnicas. São Paulo, Atlas, 1985. 287p.

TOLEDO, J.C.: “Gestão da mudança da qualidade do produto." Gestão \& Produção, v.1, n.2, p.104125, ago, 1994.

\section{COLLABORATION BETWEEN CUSTOMERS AND SUPPLIERS IN THE PRODUCT DEVELOPMENT PROCESS: CASE STUDIES IN AUTO PARTS INDUSTRY}

\section{Abstract}

One of the current practices used by businesses, regarding increased productivity, quality and the reduction of product development lead time, is the involvement of suppliers. There are strong 
indications that this participation increases productivity and reduces both the development lead time and the possibility of delays in the project, and facilitates the incorporation of new technologies. One of the most conflicting points is how great the effect is in terms of quality of the product design. To evaluate this two case studies in automotive suppliers were conducted. In each one, the variables of integration and scope in development projects were compared between the company which produces specific auto parts and four of its clients which assemble vehicles, evaluating their influence on the quality of product design. The main results are: the formal mechanisms of client-supplier collaboration in product development were homogeneous, comparing several clients of one supplier; the increase of the scope positively affected the quality of the product design.

Key words: product development, collaboration between customers and suppliers, quality of product design, auto parts industry. 